\title{
Calculating "Hydrothermal time" to quantify seed germination of tall fescue
}

\author{
S. SHARIFIAMINA, D.J. MOOT and M. BLOOMBERG \\ Faculty of Agriculture and Life Sciences, PO Box 85804, \\ Lincoln University, Lincoln 7647, Christchurch, New Zealand
}

Shirin.sharifi@lincolnuni.ac.nz

\begin{abstract}
The objective of this study was to quantify the combined effects of temperature and moisture on germination of tall fescue seed. Seeds were incubated for up to 50 days at a range of constant temperatures $\left(5-35^{\circ} \mathrm{C}\right)$ and germinated at five water potentials $(0,-0.18,-0.37$, -0.63 and $-0.95 \mathrm{MPa})$. The maximum final germination percentages were 94 to 98 at $15-30^{\circ} \mathrm{C}$ when water was not limited $(0 \mathrm{MPa})$. Germination rate increased linearly from 5 to $27.5^{\circ} \mathrm{C}$, and then decreased linearly from 27.5 to $32.5^{\circ} \mathrm{C}$. Extrapolation of the sub-optimal temperatures identified a base temperature of $3.5 \pm$ $0.5^{\circ} \mathrm{C}$ and an optimum temperature of $27.5^{\circ} \mathrm{C}$. More negative water potential indicative of drier conditions, delayed germination and reduced germination rate. The average base water potential was $-0.95 \mathrm{MPa}$ at the suboptimal range of temperatures. An optimum range of germination $(80-100 \%)$ occurred when temperatures were between 10 and $30^{\circ} \mathrm{C}$ and water potential was between 0 to $-0.37 \mathrm{MPa}$ (moderate stress). These results provide a matrix of soil temperature and moisture conditions that are expected to result in successful germination and therefore provide the maximum opportunity for emergence of tall fescue seedlings.
\end{abstract}

Keywords: Festuca arundinacea, 'Finesse Q', hydrothermal time

\section{Introduction}

Soil moisture is a limiting factor in the establishment of temperate pastures in New Zealand. This is particularly an issue in a dry autumn when the majority $(85 \%)$ of pastures are established (Milne 2011); warm, dry soil may inhibit the germination of some species more than others. This will have consequences for pasture composition in the short and longer term. To reduce the risk of establishment failure, it is important to understand how soil moisture and temperature interact with pasture establishment.

Tall fescue has long been promoted as a useful species for many regions of New Zealand (Milne 2011). It is characterised as highly productive in summer, drought tolerant and persistent (Cowan 1956; Cregan 1978). Tall fescue is able to decrease the effects of drought stress through reduction in transpiration rate, leaf rolling and stomatal closure (Renard \& Francois
1985). This means annual water use efficiency of tall fescue is higher than perennial ryegrass (Smeal et al. 2005). However, relative to perennial ryegrass it is slow to establish (Moot et al. 2000).

The first stage of pasture establishment is germination, which sets the potential maximum number of seedlings that could emerge. Therefore, it is important to understand seed germination in response to the main environmental factors of temperature and water potential. These determine the germination rate and total germination percentage individually or mutually (Baskin \& Baskin 1998). This study quantifies how the combined effects of different temperatures $(\mathrm{T})$ and water potentials $(\Psi)$ affect germination of tall fescue seeds.

In non-dormant seeds, temperature has the primary effect on the rate of germination (Moot et al. 2000). To quantify this, three cardinal temperatures were defined as the base or minimum $\left(\mathrm{T}_{\mathrm{b}}\right)$, optimum $\left(\mathrm{T}_{\mathrm{o}}\right)$ and maximum $\left(\mathrm{T}_{\max }\right)$ at which a species is able to germinate (Angus et al. 1981). $\mathrm{T}_{\mathrm{o}}$ was the temperature at which germination occurs in the shortest duration. $\mathrm{T}_{\mathrm{b}}$ and $\mathrm{T}_{\max }$, were the lowest and highest temperatures, respectively, at which a particular seed species/cultivar will germinate. Temperatures between $T_{b}$ and $T_{o}$ were "sub-optimal", while those higher than the optimum $\left(\mathrm{T}>\mathrm{T}_{\mathrm{o}}\right.$ ) were "supra-optimal". The process of defining $\mathrm{T}_{\mathrm{b}}, \mathrm{T}_{\mathrm{o}}$ and $\mathrm{T}_{\max }$ has been outlined for many tropical and temperate species (Angus et al. 1981) including those used for temperate pastures (Moot et al. 2000; Lonati et al. 2009). Species differences in cardinal temperatures can be used to understand species compatibility in a pasture mix and explain which sowing conditions are most likely to result in successful species establishment. When seeds are sown into soil with adequate water, germination and emergence can be predicted based on the daily accumulation of thermal time. When temperatures are in the sub-optimal range, thermal time or heat units in excess of $T_{b}$ received by the seeds can be accumulated to predict the time of germination and emergence. This allows progress to the completion of different phenological stages in response to temperature to be explained by mathematical models as outlined in Equations 1 and 2 for germination (Angus et al. 1981).

$$
\begin{aligned}
& \text { OT }(\mathrm{g})=\left(\mathrm{T}-\mathrm{T}_{\mathrm{b}}\right) \mathrm{t}_{\mathrm{g}} \text { and } \\
& \mathrm{GR}=1 / \mathrm{t}_{\mathrm{g}}=\left(\mathrm{T}-\mathrm{T}_{\mathrm{b}}\right) / \mathrm{OT}(\mathrm{g})
\end{aligned}
$$


when GR is the germination rate, $\theta \mathrm{T}$ is a thermal time constant, $\mathrm{T}$ is the medium temperature and $\mathrm{t}_{\mathrm{g}}$ is time to germination of the $\mathrm{g}^{\text {th }}$ percentile of the seeds. In this model, $\mathrm{Tb}$ is estimated from the temperature where $\mathrm{GR}=0$ for a specific seed percentile $(\mathrm{g})$. This is usually constant for all seeds in the seed population. Variation in the time to germination ( $\mathrm{tg}$ ) for each seed percentile is modelled by varying the value of the thermal time constant for each percentile $(\Theta T(g))$.

The caveat in using the accumulated thermal time approach is that moisture is non-limiting. However, in many agricultural contexts such as autumn sown herbage species in summer dry regions in New Zealand this is not always the case. To predict the impact of moisture on germination the concept of "Hydrothermal time" has been proposed (Bradford 1995; Gummerson 1986), which is based on the assumption that at a given temperature, changing moisture (water potential) conditions will affect germination. The impact of water potential on germination for herbage species was quantified by McWilliam et al. (1970). They showed that perennial ryegrass was comparatively unaffected by changes in water potential relative to other common herbage species when germinated at $20^{\circ} \mathrm{C}$, but their study did not include tall fescue.

The relationship between seed germination rate and water potential has been mathematically described as:

$$
\theta T=(\Psi-\Psi b(g)) t g
$$

when $\theta T$ is the hydro-time constant, $\Psi$ the ambient water potential, and $\Psi b(\mathrm{~g})$ the base water potential for the $\mathrm{g}^{\text {th }}$ percentile of the seeds below which no germination occurs. Using a single value of $g=50 \%$ gives a common value to compare across treatments. This model assumes that the base water potential changes within a seed population, but does not vary significantly with increasing or decreasing temperature between the base and optimum temperatures. The variation in seed base water potential within a population can usually be described by a normal distribution (Bradford 2002; Finch-Savage 2004).

By combining Equations 2 and 3, Gummerson (1986) proposed "Hydrothermal time" as a method to model seed germination under different combinations of temperature and moisture. Bradford $(1995,2002)$ expanded the approach as described in Equation 4:

$\theta H T=[\Psi-\Psi b(g)](T-T b) t(g)$

when $\theta \mathrm{HT}\left(\mathrm{MPa}^{\circ} \mathrm{Cd}\right)$ is a hydrothermal time constant (Gummerson 1986; Bradford 1995) that has a unique value for a seed population, $\Psi b(\mathrm{~g})$ the base water potential for the $\mathrm{g}^{\text {th }}$ percentile in a seed population (MPa), $T_{b}$ the base temperature for seed germination $\left({ }^{\circ} \mathrm{C}\right)$ and $\mathrm{t}(\mathrm{g})$ the time for the $\mathrm{g}^{\text {th }}$ percentile to germinate (days or hours). For this research the $50^{\text {th }}$ percentile was used to illustrate the concept. Based on the hydrothermal time model, under a constant temperature and water potential, the $50^{\text {th }}$ percentile of the seed population will germinate when they have accumulated a certain quantity of hydrothermal time.

To describe the hydrothermal time approach results from tall fescue seed germination under a range of constant thermal and water potential conditions were used. The initial step was confirmation of the reported thermal time requirements for tall fescue (Moot et al. 2000; Zhang et al. 2012) using germination rate at different temperatures. The response to water potential was then quantified with temperature set a $T_{0}$. This enabled the base water potential to be defined and changes in $\Psi b(\mathrm{~g})$ were examined as water potential and temperature were altered.

\section{Materials and methods}

Tall fescue ('Finesse Q') seeds supplied by Seed Force Ltd, Christchurch, New Zealand, were incubated for at least 50 days in the dark, in constant controlled temperatures set at $5,10,15,20,25,30,32.5$ and $35^{\circ} \mathrm{C}$ and under five water potentials $(0,-0.18,-0.37$, -0.63 and $-0.95 \mathrm{MPa}$ ). A water potential of $-0.18 \mathrm{MPa}$ is equivalent to $18 \%$ moisture content for a silt loam or $33 \%$ moisture content in a clay soil (Saxton et al. 1986), while in contrast, comparable data for $-0.95 \mathrm{MPa}$ water potential were 15 and $25 \%$ moisture content, respectively.

Solutions with different water potentials were created using Polyethylene Glycol (PEG), as described by Hardegree \& Emmerich (1990) (Equation 5):

$$
\Psi=0.130[\mathrm{PEG}]^{2} \mathrm{~T}-13.7[\mathrm{PEG}]^{2}
$$

when $\Psi$ is the osmotic potential of a solution of PEG 8000 (polyethylene glycol, molecular weight $8000 \mathrm{~g} /$ $\mathrm{mol})$ in water (MPa), [PEG] is the concentration of PEG 8000 in water ( $\mathrm{g}$ PEG $8000 / \mathrm{g} \mathrm{H}_{2} 0$ ) and $\mathrm{T}$ is the solution temperature in ${ }^{\circ} \mathrm{C}$. Different PEG concentrations result in different water potentials. The water potential of the solutions was checked by an Osmometer (Wescor Inc, Logan, Utah, U.S.A.) to ensure that each solution had the targeted water potential at the beginning of the experiment. The osmotic potential of the solutions was also checked weekly for $5-27.5^{\circ} \mathrm{C}$ temperatures and every 4 days for $30^{\circ} \mathrm{C}$ and higher temperatures. This ensured that the osmotic potential of the solutions did not change due to evaporation during the experiment. Three replicates were used as a factorial combination of the constant temperatures and water potentials. To minimise fungal growth, 50 intact grass seeds were dusted with Thiram (Tetramethylthiuram disulphide) for each replicate and were placed on Whatman No.2 germination paper in $750 \mathrm{~mm}^{2}$ plastic trays. This resulted in 150 seeds per water potential/temperature combination. Then, $10 \mathrm{ml}$ of the relevant PEG solution was added to each container to ensure that the water potential was unchanged during the experiment. After 


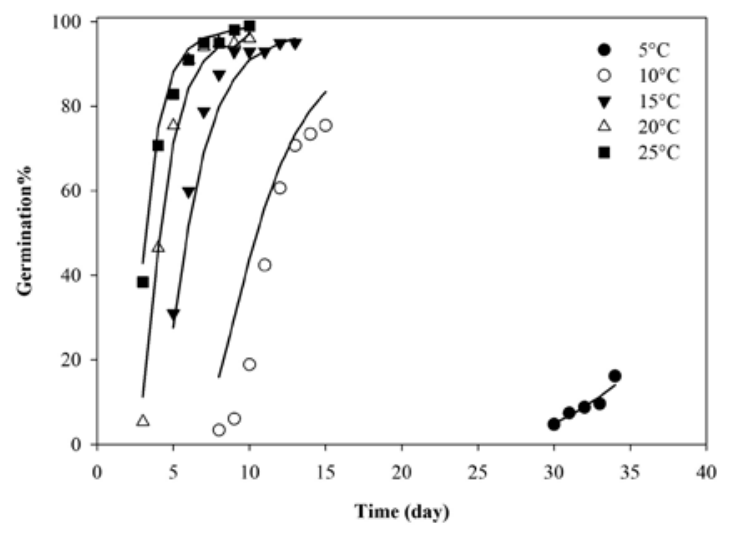

Figure 1 Germination percentages of tall fescue seeds at zero water deficit $(0 \mathrm{MPa})$, under different temperatures by time (day). The symbols are the actual data, and the lines are the time courses predicted by the hydrothermal time model.

the seeds were placed in germination containers, a plastic snap-top was secured and trays were placed in incubators at the specified temperatures. Each container was randomly placed within the incubator and then its location changed systematically on a daily basis to alleviate any small spatial differences in air temperature that could result from uneven air circulation in the incubators.

The number of germinated seeds was counted every 12 hours (when $\Psi=0 \mathrm{MPa}$ and $\mathrm{T}>10^{\circ} \mathrm{C}$ ) and every 24 hours for all other treatments. Seeds were considered to have germinated when the radicle protruded more than $2 \mathrm{~mm}$ from the seed coat (Ariefdjohan et al. 2004). At each measurement, germinated seeds were removed from the trays and the number counted and recorded.

\section{Data analysis}

Germination rates $(1 / \mathrm{d})$ were considered as the inverse of time to germination for a given fraction $(50 \%)$ of the germinated seeds $\left(1 / \mathrm{t}_{(\mathrm{g})}\right)$ in each replicate and reported as the average of the germination rate for three replicates of each treatment. Two-stage linear regressions were fitted to germination rate versus temperature using Genstat 16.1 (VSN International Ltd). Thermal time constant for $50 \%$ of the seeds to germinate $\theta \mathrm{T}\left({ }^{\circ} \mathrm{Cd}\right)$ was calculated as the inverse of the slope of the two-stage linear regressions which were fitted to germination rate versus temperature at sub- and supra-optimal range of temperatures.

Seed base water potentials at different temperatures, were calculated using generalised linear models (GLMs) with a probit (inverse of cumulative normal distribution) link function in Genstat 16.1. Predicted germination percentiles are presented as percentages. The binomial error distribution of the dependent variable was taken into account as a link function (Hay \& Bloomberg 2014).

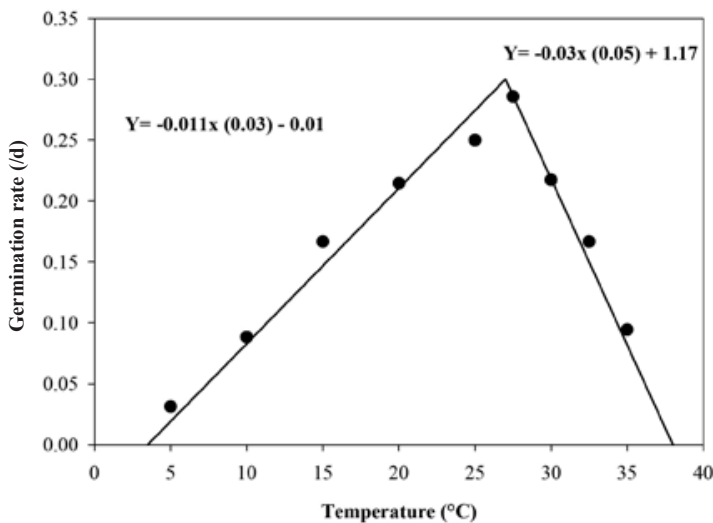

Figure 2 Rate to achieve $50 \%$ germination of tall fescue seeds under different temperatures. The regression line forced through the base temperature $\left(3.5^{\circ} \mathrm{C}\right)$.

\section{Results \\ Germination responses to temperature over time (thermal time)}

As temperature increased from $5-27.5^{\circ} \mathrm{C}$, tall fescue seed germination was faster and the number of germinated seeds increased (Figure 1). At $5^{\circ} \mathrm{C}$, seed germination started 30 days after sowing but only $16 \%$ had germinated at day 34 . At $25^{\circ} \mathrm{C}$ most of the seeds germinated in 3 days and the final germination on day 10 was $99 \%$. Under the same conditions ( $0 \mathrm{MPa})$, germination was delayed (5 and 10 days) and final percentages were reduced to 26 and $10 \%$ at 32.5 and $35^{\circ} \mathrm{C}$, respectively. Across all temperatures there was an exponential decline in the time to germination to a minimum of 3 days as temperature increased from 5 to $27.5^{\circ} \mathrm{C}$. The increase in time to germination at higher temperatures $\left(32.5\right.$ and $\left.35^{\circ} \mathrm{C}\right)$ implies these were in the supra-optimal range. Using the inverse of time (1/ days) to calculate the rate of germination (Equation 1) allowed the cardinal temperatures to be defined (Figure 2).

The linear regression line fitted for $\mathrm{g}=50 \%$ of the seeds germinated gave $\mathrm{T}_{\mathrm{b}}=3.5 \pm 0.5^{\circ} \mathrm{C}$ and the thermal time constant for $50 \%$ of the seeds to germinate $(\theta \mathrm{T})$ was $100^{\circ} \mathrm{Cd}$ at sub-optimal and $40^{\circ} \mathrm{Cd}$ at supra-optimal temperatures.

\section{Germination responses to different water potentials by time (hydrotime)}

Within the range of experimental treatments, decreasing the ambient water potential (increasing water stress) in all constant temperature treatments, caused a delay in germination and a decrease in the final germination percentages (Figure 3). For example, in water at $20^{\circ} \mathrm{C}$, tall fescue seeds started germination 2 days after sowing and reached their maximum (95\%) 10 days 


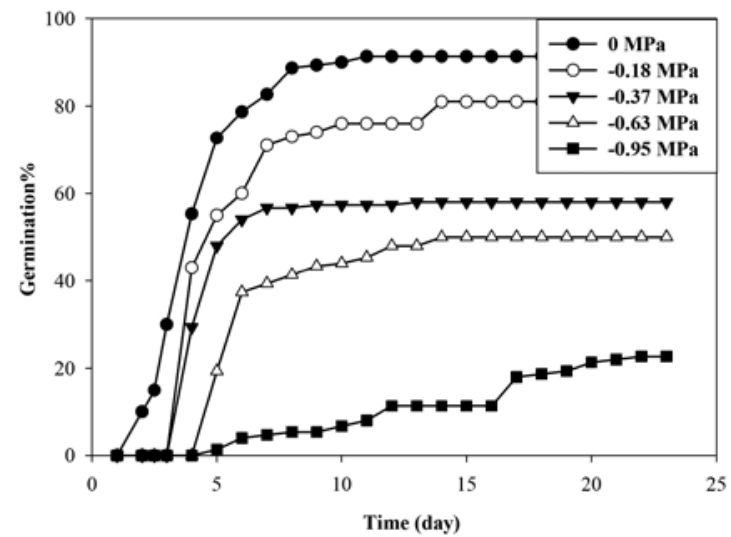

Figure 3 Time course of germination percentage of tall fescue seeds under different water potentials $(0,-0.18,-0.37,-0.63-0.95 \mathrm{MPa})$ at a constant temperature $\left(20^{\circ} \mathrm{C}\right)$.

after sowing. At $-0.63 \mathrm{MPa}$, there was a 1 day delay in germination and a final seed germination of $70 \%, 18$ days after sowing.

Determining germination rates $(1 / \mathrm{tg})$ for the $10^{\text {th }}$, $30^{\text {th }}, 50^{\text {th }}$ and $70^{\text {th }}$ percentile of the seed germination against water potentials showed a linear reduction in germination rate as water potential decreased from 0 to $-0.95 \mathrm{MPa}$. The difference in base water potentials $(\Psi b(\mathrm{~g}))$ for these different germination percentages followed a normal distribution. The base water potential $\left(\Psi b_{(50)}\right)$ calculated at sub-optimal temperatures was between $-1.1 \mathrm{MPa}\left(\mathrm{T}=10^{\circ} \mathrm{C}\right)$ and $-0.97 \mathrm{MPa}\left(\mathrm{T}=25^{\circ} \mathrm{C}\right)$. Increasing temperature above $\mathrm{T}_{\mathrm{o}}$ (supra-optimal temperatures) caused an increase in the base water potential to $-0.68 \mathrm{MPa}$, thus reducing the rate of hydrotime accumulation (Equation 3).

The fastest germination rate for tall fescue occurred at the optimum temperature $\left(25^{\circ} \mathrm{C}\right)$ in water. The response surface shows the impact of decreased water potential at each temperature (Figure 4). It highlights that at optimum temperature, rapid germination $(\mathrm{GR}=0.2 / \mathrm{d})$ occurred even at moderate $(-0.37 \mathrm{MPa})$ water stress. As temperatures moved away from the optimum, the germination rate declined rapidly at supra-optimal temperatures and mild $(-0.18 \mathrm{MPa})$ water stress. Figure 4 also shows that, when temperature was between 15 $30^{\circ} \mathrm{C}, 50 \%$ of the final germination occurred within $\leq 6$ days even at $-0.63 \mathrm{MPa}$.

The shallow gradient for sub-optimal temperatures suggests less impact of water stress on germination than at supra-optimal temperatures. The second factor to consider was the total germination percentage achieved under the same combination of temperatures and moisture stress. Figure 5 shows there was little or no impact on the final germination percentage of the different combinations of temperature and water stress until severe water stress $(-0.63 \mathrm{MPa})$ occurred.

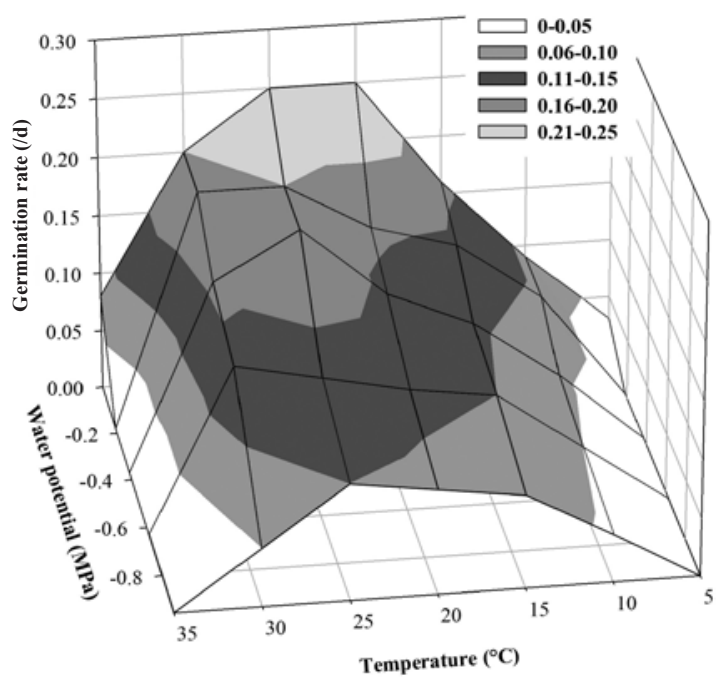

Figure 4 Rate to achieve $50 \%$ germination of tall fescue seeds $\left(\mathrm{Gr}_{(50)}=0.135 \pm 0.015\right)\left(\psi-\psi_{b}(50)\right)+$ $0.0066 \pm 0.0006)(T-T b)-0.0066 \pm 0.0006))$, under different temperatures $\left(5-35^{\circ} \mathrm{C}\right)$ and different water potentials (0 to $-0.95 \mathrm{MPa}$ ).

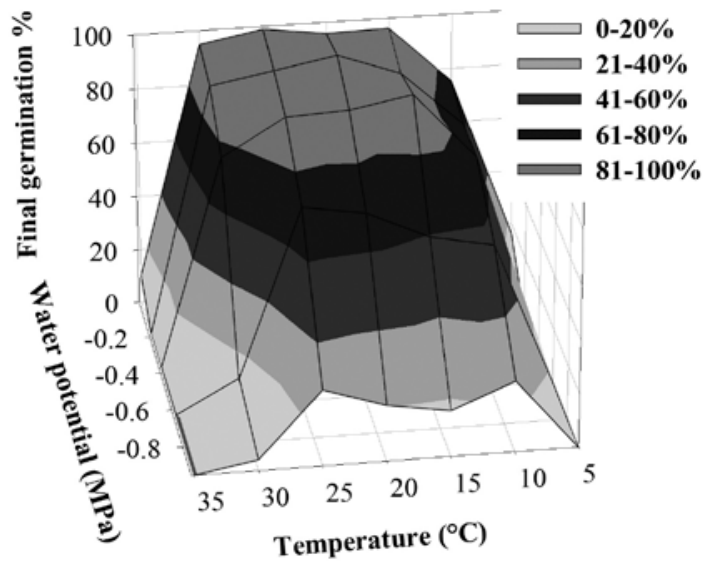

Figure 5 Final germination percentage of tall fescue under different temperatures $\left(5-35^{\circ} \mathrm{C}\right)$ and different water potentials ( 0 to $-0.95 \mathrm{MPa})$.

When temperature was $15-25^{\circ} \mathrm{C}, \geq 60-80 \%$ of the seeds germination occurred when moisture was between 0 and $-0.63 \mathrm{MPa}$. Between $40-60 \%$ of the seeds germination happened under the same water potential range when temperature was $10^{\circ} \mathrm{C}$.

\section{Discussion}

The rate of germination under different temperature and moisture regimes affects the ability of a species to establish. Those with rapid establishment have earlier access to limited resources, particularly light, nutrients and soil moisture. Tall fescue has a higher thermal time requirement for germination than perennial ryegrass 
(Moot et al, 2000). Data from this study have quantified the additional impact of moisture on germination.

When $\Psi$ was not limiting (0 MPa), the rate of germination for tall fescue was solely temperaturedependent, and there was no evidence that temperature within the range $5-27.5^{\circ} \mathrm{C}$ limited the final germination percentage (Figure 1). As temperature decreased, there was an increase in the number of days taken to germinate (Figure 1) but the thermal time accumulation was constant at $100^{\circ} \mathrm{Cd}$ (Figure 2). Seedling vigour is often correlated with germination rate and involves the rate of extension of both the root and the shoot. The correct combination of base temperature and thermal requirements is required to accurately predict when germination and subsequently seedling emergence will occur.

In the current study, the final germination of Finesse Q was $>90 \%$ at 25 and $30^{\circ} \mathrm{C}$, and decreased to 26 and $10 \%$ at 32.5 and $35^{\circ} \mathrm{C}$, respectively. This is consistent with Moot et al. (2000) findings who showed Festuca rubra and $F$. ovina germination was $>70 \%$ at $25.5^{\circ} \mathrm{C}$ reducing to 4 and $24 \%$, respectively, at $35.6^{\circ} \mathrm{C}$. The base temperatures estimated for all percentiles calculated from the present study were consistent and conservative $\left(3.5 \pm 0.5^{\circ} \mathrm{C}\right)$. Values were higher than the 0.6 and $1.1^{\circ} \mathrm{C}$ reported by Moot et al. (2000). The variation in reported base temperature for germination of tall fescue may reflect cultivar differences. For example, Zhang et al. (2012) reported a range of base temperatures between 5.1 and $11.4^{\circ} \mathrm{C}$ for 'Flecha AR542' and $6-8.3^{\circ} \mathrm{C}$ for 'Advance' tall fescue. The higher values for 'Flecha AR542' may reflect its Mediterranean origin and classification as a winteractive cultivar compared with the more summer-active 'Advance' and 'Finesse Q'. The base temperature values Zhang et al. (2012) reported for 'Advance' were also higher than reported for most temperate species, and those reported by Lonati et al. (2009). It is possible these were overestimated, because there is evidence of germination at temperatures below than those reported as the base temperature. The overestimation of base temperatures is a common artefact of estimation from linear regression. Bonhomme (2000) showed that there was usually a non-linear response to germination rate as temperatures neared the base temperature. Thus, care must be taken when stating base temperatures as they will be dependent on the range of temperatures used in their estimation and the model fitted (Andruecci et al. 2016).

In this study, the final germination percentages were 94 to $98 \%$ at $15-30^{\circ} \mathrm{C}$ when there was no moisture limitation $(0 \mathrm{MPa})$. These are similar to previous reports and show the optimum temperature range was similar across studies. Zhang et al. (2012), reported final germination percentages of 90 to $100 \%$ for 'Flecha
AR542' and 'Advance' in the range of $15-27^{\circ} \mathrm{C}$, giving maximum germination rates similar to the 0.33 /d found in the current study at $27.5^{\circ} \mathrm{C}$. Their calculated thermal time requirements for $50 \%$ seed germination were 52.4 (Flecha AR542) and $69.4^{\circ} \mathrm{Cd}$ (Advance) at sub-optimal temperatures. These are low compared with the $100^{\circ} \mathrm{Cd}$ calculated in this study. The difference probably reflects different base temperatures used to accumulate thermal time. This is one reason why a common $T_{b}=0$ was sometimes calculated to enable comparisons among experiments and species (Moot et al. 2000).

Based on the current study, even if there was adequate moisture available, soil temperatures higher than $27.5^{\circ} \mathrm{C}$, delayed germination of tall fescue seeds. Such temperatures are common for dryland soil surfaces in summer and autumn (Watson et al. 1996). Under the same moisture conditions (0 MPa), temperatures higher than $32.5^{\circ} \mathrm{C}$ inhibit germination of tall fescue. Increasing moisture stress (decreased water potential) also caused a decrease in germination rate. However, by decreasing water potential from 0 to $-0.37 \mathrm{MPa}$ at $15-25^{\circ} \mathrm{C}$, final germination percentages were not changed. A water potential of $-0.18 \mathrm{MPa}$ also did not change final germination at $30^{\circ} \mathrm{C}$. However, $-0.37 \mathrm{MPa}$ and $-0.63 \mathrm{MPa}$ of moisture stress at $30^{\circ} \mathrm{C}$ resulted in 76 and $12 \%$ final germination. On-farm, this suggests that in dry autumn conditions soil temperatures of at least $15^{\circ} \mathrm{C}$ will be required for high levels of germination.

\section{Conclusion}

These results suggest that for rain-fed pastures, if the average soil temperature was $15-25^{\circ} \mathrm{C}$ and moisture stressed $(-0.37 \mathrm{MPa})$, more than $90 \%$ of the sown 'Finesse Q' seeds would germinate before seedling emergence. For dryland autumn sown pastures, the average soil temperature can be higher than $30^{\circ} \mathrm{C}$ when over $70 \%$ of the seeds were expected to germinate under moisture stress (-0.18 and $-0.37 \mathrm{MPa})$. Moisture stress beyond $-0.37 \mathrm{MPa}$, typical of dry soils, caused a rapid decline in germination. In this situation, sowing tall fescue seeds is not recommended particularly in light sandy soils.

\section{ACKNOWLEDGEMENTS}

The $\mathrm{PhD}$ stipend for the first author was funded by Callaghan Innovation research Ltd. Mr Roland Stead supported consumables. Stephen Stilwell provided technical assistance.

\section{REFERENCES}

Andreucci, M.; Black, A.; Moot, D.J. 2012. Cardinal temperatures and thermal time requirements for germination of forage brassicas. Proceedings of the Agronomy Society of New Zealand 42: 181-191. 
Angus, J.F.; Cunningham, R.B.; Moncur, M.W.; Mackenzie, D.H. 1981. Phasic development in field crops I. Thermal response in the seedling phase. Field Crops Research 3: 365-378.

Ariefdjohan, M.; Nelson, P.; Singh, R.; Bhunia, A.; Balasubramaniam, V.; Singh, N. 2004. Efficacy of high hydrostatic pressure treatment in reducing Escherichia coli $\mathrm{O} 157$ and Listeria monocytogenes in alfalfa seeds. Journal of Food Science 69: M117-M120.

Baskin, C.C.; Baskin, J.M. 1998. Rate of germination. pp. 17-19. In: Seeds ecology, biogeography, and evolution of dormancy and germination. Elsevier, Lexington, Kentucky, United States of America.

Bewley, J.D.; Black, M. 1994. Seeds. Plenum Press, London, England. pp. 33.

Bonhomme, R. 2000. Bases and limits to using 'degree. day'units. European Journal of Agronomy 13: 1-10.

Bradford, K.J. 1995. Water relations in seed germination. pp. 351-396. In: Seed development and germination. Eds. Kigel, J.; Galili, G. Marcel Dekker, New York.

Bradford, K.J. 2002. Applications of hydrothermal time to quantifying and modeling seed germination and dormancy. Weed Science 50: 248-260.

Cowan, J.R. 1956. Advances in agronomy. Academic Press, US. pp. 423.

Cregan, P. 1978. Tall fescue [pasture grass]. Bulletin, New South Wales, Australia.

Finch-Savage, W.E. 2004. The use of population-based threshold models to describe and predict the effects of seedbed environment on germination and seedling emergence of crops. pp. 51-96. In: Handbook of seed physiology. Applications to Agriculture. Eds. Benech-Arnold, R.L.; Sanchez, R.A. The Reference Haworth Press, Binghamton, New York.

Hay, F.R.; Mead, A.; Bloomberg, M. 2014. Modelling seed germination in response to continuous variables: use and limitations of probit analysis and alternative approaches. Seed Science Research 24: 165-186.

Gummerson, R. 1986. The effect of constant temperatures and osmotic potentials on the germination of sugar beet. Journal of Experimental Botany 37: 729-741.

Hardegree, S.P.; Emmerich, W.E. 1990. Effect of polyethylene glycol exclusion on the water potential of solution-saturated filter paper. Plant Physiology 92: 462-466.

Labouriau, L.G.; Osborn, J.H. 1984. Temperature dependence of the germination of tomato seeds. Journal of Thermal Biology 9: 285-294.

Lonati, M.; Moot, D.J.; Aceto, P.; Cavallero, A.; Lucas, R.J. 2009. Thermal time requirements for germination, emergence and seedling development of adventive legume and grass species. New Zealand Journal of Agricultural Research 52: 17-29.

McWilliam, J.; Clements, R.; Dowling, P. 1970. Some factors influencing the germination and early seedling development of pasture plants. Crop and Pasture Science 21: 19-32.

Milne, G.D. 2011. Can pasture persistence be improved through the use of non-ryegrass species? Pasture Persistence Symposium. Grassland Research and Practice Series 15: 157-162.

Moot, D.; Scott, W.; Roy, A.; Nicholls, A. 2000. Base temperature and thermal time requirements for germination and emergence of temperate pasture species. New Zealand Journal of Agricultural Research 43: 15-25.

Renard, C.; Francois, J. 1985. Effects of increasing water stress on simulated swards of Festuca arundinacea Schreb under wind tunnel conditions. Annals of Botany 55: 869-879.

Saxton, K.; Rawls, W.J.; Romberger, J.; Papendick, R. 1986. Estimating generalized soil-water characteristics from texture. Soil Science Society of America Journal 50: 1031-1036.

Smeal, D.; O’Neill, M.; Arnold, R.N. 2005. Forage production of cool season pasture grasses as related to irrigation. Agricultural Water Management 76: 224-236.

Watson, R.N.; Harris, S.L.; Bell, N.L.; Neville, F.J. 1996. Deferred grazing to enhance white clover content in pastures (Abstract). Agronomy Society of New Zealand Special Publication No. 11: 154.

Zhang, H.; McGill, C.R.; Irving, L.J.; Kemp, P.D.; Zhou, D. 2013. A modified thermal time model to predict germination rate of ryegrass and tall fescue at constant temperatures. Crop Science 53: 240-249. 